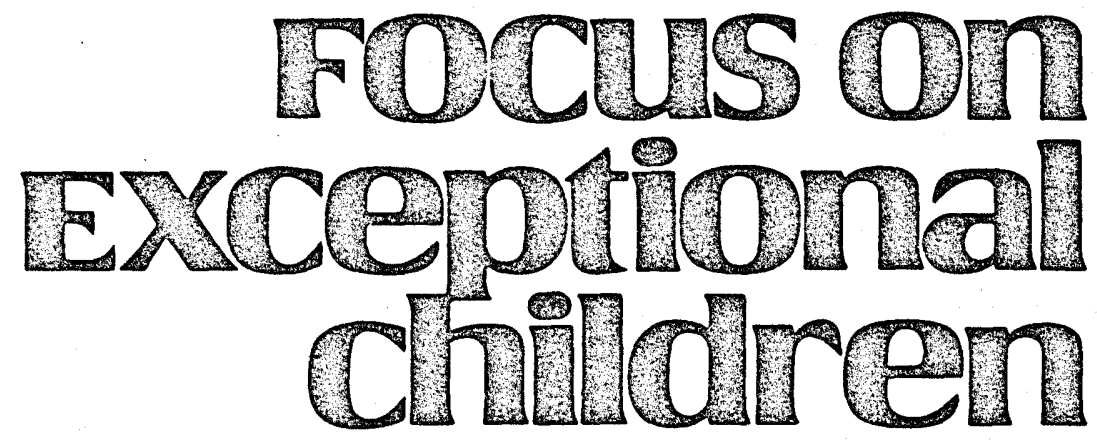

\title{
Developing Self-Regulated Learners
}

\author{
Steve Graham, Karen R. Harris, and Robert Reid
}

An important characteristic of human beings is our ability to understand and regulate our own behavior. Theologians, philosophers, and psychologists have long viewed self-control as a distinguishing characteristic of the human species, and for a variety of religious, political, philosophical, and practical reasons, the call to personally cultivate self-understanding and self-control has been sounded repeatedly throughout the ages (Zimmerman \& Schunk, 1989). The philosopher Aristotle, for instance, praised the virtues of self-awareness. Likewise, the notable American statesman and inventor Benjamin Franklin was a staunch proponent of self-regulation. He used an assortment of self-regulation procedures in his own struggles for self-improvement. At one point during his life, he defined 13 virtues (e.g., temperance, order) that he wished to develop, established the goal of increasing each virtue in turn during the space of a week, monitored instances of success and failure, and recorded the daily results. If, at the end of the week, no offenses were recorded against the virtue, he extended his goal to include the next virtue listed (cf. Zimmerman \& Schunk, 1989).

Students with special needs can use the same types of self-regulation procedures to improve their academic performance and interactions in social situations (cf. Gresham, 1985; Hallahan \& Sapona, 1983; Harris, 1982; Harris \& Graham, in press a). They can apply selfregulation procedures such as goal setting, self-monitoring (which includes self-assessment and self-recording of performance), self-instructions, and contingent self-reinforcement to academic tasks.

\section{THE RATIONALE FOR SELF-REGULATION}

People use self-regulatory procedures such as goal setting, self-monitoring, and selfevaluation to help them accomplish specific tasks. Just as self-regulation procedures such as goal setting can be used to organize a person's overall approach to a task, they also can play a contributing, but less persuasive, role in how a person accomplishes a task. Self-regulatory mechanisms often are combined (as basic building blocks), for instance, with other cognitive routines to form a program for accomplishing a specific task (Brown \& Campione, 1981). Scardamalia and Bereiter (1985) suggested that in addition to contributing to the immediate accomplishment of a task, self-regulatory mechanisms can further contribute to development

Steve Graham and Karen R. Harris are Associate Professors at the University of Maryland, College Park; Robert Reid is an Assistant Professor at the University of Nebraska, Lincoln. Authorship for this article was determined alphabetically. 
of the cognitive system. The use of self-assessment, for example, generates information that may change how a person approaches a task.

These uses of self-regulation can be illustrated further by examining several real-life examples. First, a runner we know uses goal setting to organize and direct her running program. She sets weekly distance goals, monitors her progress daily, and reinforces herself with praise or more concrete rewards when she meets her goals. Second, many children we have observed use self-regulation procedures in combination with task-specific cognitive strategies to help them accomplish academic assignments. To get ready for a spelling test, for instance, one of our former students first did a self-test to determine which words he needed to study. He then studied these words using a specific word study strategy. During the course of study, he periodically reassessed his progress to determine when he knew the words well enough to earn a passing grade.

Similarly, in our own program of research (see Graham, Harris, MacArthur, \& Schwartz, 1991; Harris \& Graham, in

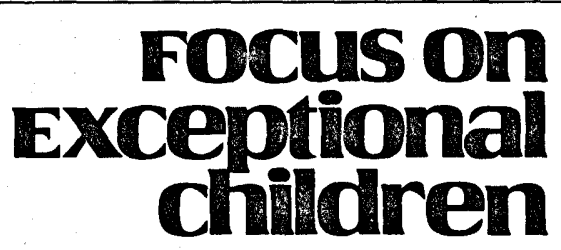

ISSN 0015-511X FOCUS ON EXCEPTIONAL CHILDREN (USPS 203-360) is published monthly except June, July, and August as a service to teachers, special educators, curriculum specialists, administrators, and those concerned with the special education of exceptional children. This publication is annotated and indexed by the ERIC Clearinghouse on Handicapped and Gifted Children for publication in the monthly Current Index to Journals in Education (CIJE) and the quarterly index, Exceptional Children Education Resources (ECER). It is also available in microfilm from Xerox University Microfilms, Ann Arbor, MI. Subscription rates: Individual, $\$ 27$ per year; institutions, $\$ 36$ per year. Copyright (C) 1992, Love Publishing Company. All rights reserved. Reproduction in whole or part without written permission is prohibited. Printed in the United States of America. Second class postage is paid at Denver, Colorado. POSTMASTER: Send address changes to:

Love Publishing Company
Executive and Editorial Office
1777 South Bellaire Street
Denver, Colorado 80222
Telephone (303) 757-2579

Edward L. Meyen.

University of Kansas

Richard J. Whelan

University of Kansas Medical Center
Stanley F. Love

Publisher
Glenn A. Vergason Georgia State University
Holly T. Rumpler Senior Editor press b), we have taught students with learning disabilities (LD) how self-regulation procedures can help them better use the academic strategies they are acquiring. When teaching a strategy for writing, for instance, we encourage children to develop an inner dialogue (self-instructions) to guide how they apply the strategy. Moreover, we encourage students to set goals for using the strategy and monitoring its application. Combining these self-regulatory procedures with other strategy instruction components contributes to students' learning and use of academic strategies (cf. Sawyer, Graham, \& Harris, 1991) and can result in changes in how students approach and view an academic task (Graham \& Harris, in press).

The self-regulatory mechanisms that children use can be fostered and improved through instruction (Harris, 1982; O'Leary \& Dubey, 1979; Scardamalia \& Bereiter, 1985). This is especially important for students receiving special services. The problems that many students with special needs experience are related in part to problems in the self-regulation of organized strategic behaviors (cf. Harris, 1982; Licht, 1983).

The basic rationale for helping students with special needs learn to better use processes for self-regulating their behavior is to promote the development of self-regulated learnersstudents who independently plan and self-regulate goal-directed behaviors. Improving students' self-regulation abilities is important in academic settings for at least three reasons (Harris \& Graham, in press b).

1. Learning to self-regulate their behaviors allows students to become more independent. In addition to the many positive benefits this creates for students, it also reduces demands on teacher time.

2. Learning to use self-regulation procedures often increases students' level of task engagement; thus, in addition to facilitating learning, it may decrease disruptive or off-task behaviors.

3. Perhaps most important, self-regulation techniques enable students to monitor and regulate their own academic performance.

In short, these procedures empower students.

Four basic components of self-regulation are self-instructions, goal setting, self-monitoring, and self-reinforcement. Although each component is described separately here, they are closely related and can be used either independently or in combination. As mentioned, we use these same procedures as part of an instructional approach to help students with special needs develop academic strategies. We refer to this approach to strategy instruction as "self-regulated strategy develop- 
ment" and direct the reader who would like more information to Graham and Harris (1987); Graham, Harris, and Sawyer (1987); and Harris and Graham (in press a, in press b).

\section{SELF-INSTRUCTIONS}

Self-instructions involve speaking to ourselves to direct or regulate our behavior. This self-directing dialogue may be overt (spoken aloud) or covert (inside the mind). When writing, for example, authors constantly talk to themselves (either overtly or covertly). Some of this personal dialogue involves rehearsing or fine-tuning what they intend to say. Other parts of this dialogue are aimed at orienting, organizing, and structuring writers' composing behaviors. This self-speech (or private speech) is not intended for communication with others; it is directed to the self and is used to drive what the writer does.

Development of self-speech during early childhood is thought to be critical in the development of self-regulated behavior. According to Vygotsky (1934/1962), even toddlers' early egocentric speech may be a nascent form of self-regulation. Meichenbaum and Goodman (1979) noted that young children's egocentric speech can act as a self-command, as a reinforcer, or as an aid to mark the rhythm of an action. As children grow and develop, they gradually become able to use selfspeech to consciously understand situations, to focus on problems, and to surmount difficulties (Harris, 1990; Zivin, 1979).

Overt self-speech typically increases until about age 7 (Fuson, 1979; Vygotsky, 1934, 1962). It then decreases until, by ages 8 to 10 , it becomes primarily covert as the child's cognitive capabilities increase and he or she is aware that speaking aloud in the presence of others is not socially acceptable. This process may be delayed in some children, including those with learning problems (cf. Zivin, 1979). This covert self-speech is viewed as the immediate precursor to "pure thought."

Students can use self-speech or self-instructions in a variety of ways to strengthen their performance in academic situations. Self-instructions can help them understand the nature and demands of an academic assignment or problem; produce effective, relevant, and efficient strategies for accomplishing tasks; and monitor the use and effectiveness of these strategies. As other applications self-instructions in the classroom can be used to:

- direct attention to salient events, stimuli, or aspects of a problem.

- interpret or control automatic or impulsive responses.

- create and select among alternative actions.

- focus students' thinking.
- aid memory for steps and procedures.

- direct the execution of a sequence of actions or steps.

- cope with anxiety, frustration, or other emotional reactions.

- spell out criteria for success.

In addition, self-instructions can improve task orientation (resulting in a more positive approach to academic tasks), increase and maintain on-task behaviors (through increasing the amount of engaged time), and provide means for dealing with situations involving success or failure (Harris, 1982, 1990; Harris \& Graham, in press a).

To illustrate how self-instructions (and a few other selfregulation techniques you will encounter later) might work, imagine an experienced teacher beginning to plan a lesson. Because she is experienced, she has little need for self-speech as she gets ready to plan. As she begins the planning process, she engages in self-speech as well as other cognitive processes: imagining, anticipating, and self-monitoring. Her internal dialogue might go like this: "What's the point of this lesson? Okay, I want them to understand how to solve this kind of word problem." As she works, her internal dialogue consists of abbreviated messages to herself such as, "They might not be able to do ...," "Maybe this would be better," "Last year this worked pretty well." These routine steps usually are taken care of with little or no self-speech.

When encountering a problem, however, the amount of self-speech increases, resulting in statements such as, "How am I going to teach them this concept?" As she begins to work on the problem, she finds herself muttering out loud, 'No, no, no, that just won't work." Evaluating students' anticipated responses, she decides, "This is too difficult, I need a much clearer example to illustrate this point." As she continues planning, she might make the following self-reinforcement and self-evaluation statements to herself: "That's it!"; "This is going to be a great lesson." As time passes, she reaches the point at which she becomes fatigued and is tempted to stop. Coping messages help her stay on-task and meet the goal she set to finish the lesson plan: "I can do this if I just keep at it. Then I can relax and it won't bother me later and I can enjoy the rest of the evening."

\section{Forms and Levels of Self-Instruction}

Teachers can help students learn to use at least six different forms of self-instructions (each of which can be used at two different levels) (Harris \& Graham, in press a; Meichenbaum, 1977). Table 1 provides examples of each form and level. The self-instructions illustrated can help students comprehend the nature of the task or problem they are trying to solve, produce 
TABLE 1

The Basic Forms of Self-Instructions, with Examples

\section{Forms of Self-Instruction}

1. Problem Definition (Sizing up the nature and demands of the task)

2. Focusing Attention and Planning (attending to the task at hand and generating a plan)

3. Strategy (engaging and implementing strategies)

4. Self-Evaluating and Error Correcting (evaluating performance, catching and correcting errors)

5. Coping and Self-Control (subsuming difficulties or failures and dealing with forms of arousal)

\section{Self-Reinforcement (providing reward)}

\section{Examples}

\author{
What is it I have to do here? \\ What am I up to? \\ What is my first step?
}

I have to concentrate, be careful . . . think of the steps.

To do this right, I have to make a plan.

First I need to ..., then ...

First I will write--brainstorm as many ideas as I can.

The first step in writing an essay is ... .

My goals for this essay are . . ; I will self-record on ...

Oops, I missed one; that's okay-I can revise.

Am I following my plan?

Don't worry-worry doesn't help.

It's okay to feel a little anxious; a little anxiety can help.

I'm not going to get mad; mad makes me do bad.

I need to go slow and take my time.

I'm getting better at this.

Wait 'til my teacher reads this!

Hooray-l'm done!

Source: Adapted from Helping Young Writers Master the Craft: Strategy Instruction and Self-Regulation in the Writing Process by K. R. Harris and S. Graham, in press, Cambridge, MA: Brookline Books. Reprinted by permission.

strategies for tackling the problem, use the strategies generated to mediate behavior directly and effectively, evaluate and modify strategies and performance as needed, increase independence, and improve generalization and maintenance of strategic performance. Depending upon the task or problem, students might use any or all of the forms and levels of the self-instructions illustrated.

\section{Forms of Self-Instruction}

1. Problem definition statements. These require students to ascertain the nature of the task and what is required to accomplish it. One way to do this is self-questioning (cf. Wong \& Jones, 1982). Students ask themselves questions about the task and, in answering, provide possible solutions. A student might ask, "What do I need to do here? I need to write a report about the book I read; I need to remember to include the plot, character, and setting."
2. Focusing attention and planning. As the name implies, these statements help students focus on the task at hand and create a plan of action (e.g., choosing a strategy or determining appropriate steps to solve a problem). Here, a student's personal dialogue might include, "Before I start writing, I'll find the plot, character, and setting and make notes about each."

3. Strategy statements. Strategy statements help students engage and implement task-relevant or self-regulation strategies. An example might be, "I'll use my writing strategy: TAP and count. TAP means I need to consider my topic, audience, and purpose. Count means I have to think about the parts of what I'm going to write."

4. Self-evaluation and error correction statements. This type of statement helps students evaluate their progress and detect and correct errors. An example could be, "Let's see, did I include plot, character, and setting? 
Oops, I forgot setting. That's okay; I can revise."

5. Coping and self-control statements help students surmount difficulties or failures. These also can be used to deal with stress, anxiety, anger, frustration, or other feelings that interfere with performance. An older student confronted with a difficult task might say, "Okay, this isn't rocket science; I can do this," helping the student deal with fear of failure. Another example of coping and self-control statements is, "It's okay if I make a mistake; I can correct it later."

6. Self-reinforcement. These statements are used to reward progress, cope with problems, or increase persistence. Self-reinforcement statements include, "Good job" and "I'm making progress." Other examples of self-reinforcement statements are:

\section{Awesome! \\ That was my best job! \\ Wonderful! \\ Outstanding! \\ Splendid! \\ Fantastic job! \\ Excellent! \\ Keep up the good work! \\ Wow! \\ Terrific! \\ Great! \\ Nice job! \\ Well done! \\ Good job! \\ Terrific! \\ Super! \\ I'm a genius!}

When working with students, teachers need not worry about or label what category a self-statement fits into. Instead, they should focus on helping students decide what types of self-statements will aid them, and assist if necessary in their formulation. Self-statements should be in the students' own words. Student-created self-statements are preferable to those developed by the teacher. When our students have devised self-statements, they generally have used categories such as "things to help me get going" (problem definition and focusing and planning self-instructions might be used here) and "what I say when I'm finished" (self-reinforcement and selfevaluation and error correction could come into play here).

Usually, starting with a single type of self-instruction that fits a child's specific need is best. Using too many types of self-instructions all at once or too quickly may cause students to become confused or overwhelmed. After students have grown accustomed to a particular form of self-instruction, new ones can be added. We have found that students with severe learning problems can quickly master self-instructions, and are soon ready to expand their repertoire (Harris \& Graham, in press a).

\section{Levels of Self-Instruction}

Self-instructions can occur at two levels: (a) task-approach and (b) task-specific. Task-approach statements are appropriate for a wide variety of problems and situations. Task-approach statements often serve metacognitive functions, as they increase students' awareness and control of their own cognitive functioning. These global statements may be particularly useful in helping students generalize self-regulated behavior to other settings or tasks. The statement, "What do I need to do here?" is a problem definition statement at the task-approach level. Conversely, the self-statement, "I need to write down the ste $_{i} \mathrm{~s}$ in my spelling strategy" is a problem definition statement at the task-specific level. Task-specific statements are more helpful in improving performance on a given task but they typically have little potential for generalizability.

At present, it is not known if any of the six forms of self-instructions (at either level) is more effective than the others. We do not believe this is a critical issue for classroom practice, however. Students should simply be encouraged to develop self-instructions that meet their needs, regardless of the form or level. Teachers should concentrate on helping students generate both task-approach and task-specific self-instructions.

\section{Teaching Students to Use Self-Instructions}

A puzzle was rigged (it could not be successfully completed) to study the private speech of children with and without learning problems (Harris, 1986a). As expected, the normally achieving children used a number of strategies to try to complete the puzzle, and they produced a sizable amount of relevant, helpful self-speech. The children with learning problems, on the other hand, typically did not approach the task 
strategically and used irrelevant self-statements, many of which were negative. Examples of children using irrelevant self-statements included one girl who talked at length about what she would do at her Brownies meeting (which wouldn't take place for another 4 days), and a boy who sang a song about taking a trip to Idaho. Negative statements included "I hate puzzles" and "I'm no good at puzzles." Most of the students with LD stopped trying to work the puzzle before ever reaching the rigged piece.

Toward the end of the study, an adorable young man with a crewcut and horn-rimmed glasses, wearing a coat and bow tie, came to work on the puzzle. After explaining the task, the student was asked to complete the puzzle and then went to the other end of the room. Things appeared to be going as they had with the other students with LD. The student seemed to become frustrated quickly. Just when he seemed about to quit, however, he pushed himself back from the table, folded his hands in his lap, took a deep breath, and chanted, "I'm not going to get mad; mad makes me do bad." The "Little Professor" used the same self-instruction many times while working on the puzzle. He was able to fit more pieces and persisted longer than any of the other children with learning problems.

Curious as to how the little boy had come to use selfspeech in this way, his teacher was contacted. The teacher, who was not familiar with the term self-speech or research in this area, simply believed that what we say to ourselves affects what we do. During weekly class meetings students helped one another identify problem areas and develop selfstatements to deal with their problems. The Little Professor had identified getting mad as a problem that had prevented him from doing his best. Together, the class had worked out the procedure of his pushing back his chair, taking a deep breath, folding his hands, and using the self-statement. The teacher initially had helped by explaining the rationale for self-instructions, helping the students develop their own selfinstructions, modeling their use, and cuing students when the self-statement was appropriate. The Little Professor obviously had mastered use of this self-statement-including being able to generalize its use across settings.

Teaching students to use self-instructions usually is done in much the same way as it was by the Little Professor's teacher. First the teacher and student(s) discuss the importance of what we say to ourselves and how the things we say can hurt or help us. Many of our students report primarily the spontaneous use of negative self-speech, of which they readily offer examples. Next the teacher assists students in developing meaningful self-instructions in their own words. Seeing someone else (preferably a peer) successfully use self-instructions (modeling) is a critical component in the learning pro- cess. One effective technique is for teacher and student to model and share, both formally and informally, how self-instructions can be used in given situations or for specific tasks. After self-statements have been determined, students are prompted and assisted in the use of the statements as necessary. This assistance is gradually faded as the students become more able to use the self-instructions appropriately and independently.

The teacher and students should regularly and collaboratively evaluate the efficiency and effectiveness of the self-instructions learned. If a student has stopped using self-instructions, the teacher should ascertain why. In some instances students may need only a reminder to remember to use their self-statements or may need to make a slight change in their self-statements. In other cases a more extended booster session may be necessary. Self-instructions may have to be remodeled, and procedures for prompting their use might have to be reinstated.

Students can use self-instructions alone or can combine these with other self-regulation techniques such as goal setting, self-monitoring, and self-reinforcement. Students with more severe learning problems may profit from gradually learning multiple self-regulation procedures. Students who are already using effective self-regulation strategies may not require help in this area, or they may profit from developing one or two new self-regulation strategies.

\section{Practical Tips}

Self-instructions generally are most effective when they are matched to the student's verbal type and language level. As mentioned, students' self-instructions should be in their own words. Although a teacher may initially model a self-instruction or a set of self-instructions, students should individually choose the wording of their own self-instructions. Also, if a student decides on a statement created by another student, the teacher should make sure the statement is meaningful and appropriate for the second student. Self-instructions that students do not truly understand and feel comfortable with will do little good. Finally, students typically abbreviate or modify their self-instructions over time. This is desirable as long as the self-instructions continue to work, but sometimes changes in self-instructions lessen their effectiveness or subvert their purpose. Teachers should be alert to this possibility.

When teaching self-instructions, the teacher has to be enthusiastic and modeling has to be done with appropriate phrasing and inflection. Self-instructions cannot be taught in a mechanical, rote-learning fashion. The student must be an active participant and collaborator in the design, implementation, and evaluation of self-instructions. The student should 
not be viewed as merely a passive recipient. Moreover, the model (whether the teacher or a peer) must have a positive, favorable relationship with the student. Self-instructions can be modeled on an impromptu basis and in informal situations such as games, discussions, and other everyday occurrences. Even though live models are preferable, other alternatives, such as cartoon characters and drawings, have been successful aids. Written lists of statements, tape-recorded statements, and videotaped models also have been used effectively.

Another useful technique is to ask the target student to be a model for other students. This gives the target student an extra incentive to learn to use self-instructions. Videotaping students saying their self-instructions also can be motivational. One teacher we know rewards students for mastering self-instructions by videotaping them as they apply what they have learned. These videotapes are used later to show other students how selfstatements can be employed and facilitate performance.

Students have to realize that there is a connection between self-instructions and actions. Students need to know that merely saying the right things without doing the action or task will not likely be effective. If students have a great deal of difficulty achieving correspondence between saying and doing, their selfinstructions may be too difficult or inappropriate. Teachers should be sensitive to the possibility that some students may need help in developing the connection between self-instructions and the behavior or cognition they are meant to affect.

Older students, who are more aware that talking to oneself is viewed as embarrassing or inappropriate, sometimes resist overt verbalizations. Students should not be forced to use overt verbalizations (or any kind of self-regulation procedures for that matter). Nevertheless, some techniques can be employed to circumvent this. One successful tactic with older students is to present self-instructions as "thinking out loud" rather than "talking to yourself out loud" and stressing that the overt use of self-instructions will be temporary. Group discussions in which individuals, including adults, share how they use self-speech both overtly and covertly can also help. Another tactic is to explain to students that hearing them use the self-instructions is necessary initially to be sure they are doing this appropriately. Students need to be told that their eventual goal is to use the self-instructions covertly and that they can progress to this stage quite quickly. If a student continues to be reluctant about overt self-instructions, allow that student to practice away from other students who might overhear, or let the student speak into a microphone (students usually see this as different from talking out loud to themselves).

Self-instructions appropriate to students' needs and characteristics (including language and cognitive capacity) and the task at hand rarely interfere with performance. Overt verbalizations, however, can interfere with behaviors that are timed, occur quickly, require reflexive reactions, or involve complex processing (Harris \& Graham, in press a; Zivin, 1979). For example, we have found that complex self-instructions are cumbersome for many young children who are learning to print (Graham, 1983). Self-instructions should be evaluated carefully by the student and the teacher alike to ensure that they are both appropriate and do not interfere with performance.

\section{GOAL SETTING}

Goal setting provides a useful heuristic for attacking many educational difficulties. For instance, a student writing a term paper for a history class might decide to write a paper on Abraham Lincoln that will be 10 pages long, focus on the Civil War, and receive at least a " $B$ " grade. The student might further operationalize some of these criteria by developing a practical plan that specifies a sequence of actions for attaining goals: "I'll get two books on Lincoln, read them to locate important events and information, make a tentative decision about what to include in the paper, and keep track of how many pages I write." While carrying out the assignment, the student might also periodically assess if the plan and goals are working out. If they are not, the student might decide to redefine the initial plans or a specific goal: "I can't cover all of this in 10 pages, so I'll make the paper a couple of pages longer."

In real life, the process of goal setting is not always this neat, nor are the goals always so clear-cut. Nevertheless, heuristics such as goal setting give learners a means for making a complex problem such as writing a term paper more manageable and less threatening (Graham, MacArthur, Schwartz, \& Voth, in press). In examining goal setting, we first consider how the act of setting goals can facilitate performance.

\section{Dimensions of Goal Setting}

Across a diverse range of tasks from increasing productivity to losing weight, goal setting has been shown to be an extremely powerful tool (Johnson \& Graham, 1990; Locke, Shaw, Saari, \& Latham, 1981). One reason goal setting is so effective is that goals work to enhance motivation. The anticipated satisfaction and desire of attaining a goal provides an incentive to mobilize and sustain effort until the goal is reached or exceeded. Goal setting is also effective because goals focus attention on what has to be accomplished and foster the development of a plan of action for obtaining the desired results.

Goals further serve an informational function by allowing a person to compare present performance against the standard 
embodied in the goal (Bandura \& Schunk, 1977; Schunk, 1985). Noting progress in obtaining a desired goal can boost one's personal sense of efficacy, which in turn can increase motivation for accomplishing the goal. For school-age children, goal setting can lead to increased task engagement, faster learning, and a heightened sense of personal accomplishment (Schunk, 1985, 1989).

\section{Goal Properties}

Goals exert their effects through their properties (Schunk, 1989). Three properties that are especially critical are specificity, difficulty, and proximity.

\section{Specificity}

Goals should supply a clear and specific standard for performance. For instance, a goal such as "Write a paper citing 20 references" will elicit better performance than a vague goal such as "Do some referencing" or no goal at all (Latham \& Yukl, 1975). Specific goals give students a clear indication of what is required. This makes it easier for them to plan and assess their progress.

\section{Difficulty}

Goal difficulty refers to how challenging a goal is for a specific person. Challenging goals lead to better performance than easy goals; goals that can be achieved with little or no effort provide little incentive to mobilize effort or resources (Johnson \& Graham, 1990). As Masters, Furman, and Barden (1977) accurately noted, "Any standard provides an incentive for improvement only until it is reached" (p. 218). A caveat, however, is in order. More difficult goals can lead to better performance only with both a commitment to obtaining the goal and the ability to achieve the goal.

\section{Proximity}

Goals also may differ in proximity. Proximal goals are near at hand and can be completed quickly (e.g., "Do ten algebra problems before the end of class today"). In contrast, distal goals can be completed only in the future (e.g., "Make a detailed observation of the mating patterns of the common sparrow"). Proximal goals produce higher levels of performance than do distal goals (Bandura \& Simon, 1977). Distal goals are often too far removed in time to stimulate a person to mobilize resources in the here and now. We have all put off distal tasks (such as that term paper) until the last minute.

In summary, goals that are specific and challenging are superior to goals that are vague and easy. Furthermore, goals that can be accomplished more immediately (proximal goals) are superior to goals that can be accomplished only in the long term (distal goals).

\section{Other Factors}

Successful goal setting also depends on a number of other factors. Two of these are feedback and participation in setting goals.

\section{Feedback}

Of particular importance is knowledge about how good a job one is doing in achieving the desired goals. Successful goal setting is dependent on feedback or knowledge of results (Locke et al., 1981). Feedback influences performance by cuing individuals to increase effort when progress is lagging, to reset easy goals to more challenging ones, and to establish new goals when they have accomplished old ones. Timely and frequent feedback is especially helpful because it encourages evaluation and control of behaviors proactively. For children, feedback can be obtained from teachers or peers, or through self-assessments. Obviously, students will be more successful in evaluating their progress when goals are explicit and easily measured.

\section{Participative Goal Setting}

Who creates or sets the goals also can influence the power of goal setting. Goals can be assigned by the teacher, determined by the student, or participative. Participative goals involve both the teacher and student in developing or selecting goals. Having a student choose one or more from a set of goals conjointly developed by the teacher and the student is one example of participative goal setting. Participative goals should be emphasized initially, as many students (especially young children and students with learning problems) have difficulty setting reasonable and realistic goals for themselves (Graham \& Harris, 1989). Thus, if possible, teachers should resist the temptation to provide students with desirable goals. Instead, teachers should involve students in the goal-setting process, as this leads to higher levels of commitment to achieve goals and a sense of ownership (Locke et al., 1981). Regardless of the approach, the teacher's ultimate objective is to have students establish their own goals independently.

In participative goal setting, teachers need to be sensitive to the match between goal selection and the individual student's ability to accomplish (or approach for accomplishing) selected goals. If selected goals repeatedly exceed a student's capabilities, the effectiveness of goal setting will be seriously undermined, possibly leading the student to devalue the goalsetting process. Mismatch between capabilities and goal difficulty can be mediated by helping students develop or access effective strategies for accomplishing the desired objective.

Obviously, acceptance of a goal and commitment to attain it are critical to the success of the goal-setting process. One way 
in which teachers can foster goal acceptance and commitment is by being supportive. Teachers should attend closely to students' opinions and feelings about goals, encourage questions, and query students on the actions they might perform to meet goals. Goals are also more likely to be accepted if they are perceived as being valuable. Unfortunately, for many students with special needs, academic goals often do not meet this criterion. One way to make academic goals more valuable to these students is to link accomplishment to an external reinforcer such as 15 minutes of free time. (Before using external rewards, however, we recommend that you consider the selfreinforcement procedures discussed later in this article.) Nothing works like success. Students who have a history of successfully meeting their goals are more likely to have the confidence to set and achieve even more demanding goals.

\section{SELF-MONITORING}

Self-monitoring occurs when a student determines whether a target behavior has or has not occurred and then records the result in some way (Nelson, 1977; O'Leary \& Dubey, 1979). Thus, by definition, self-monitoring contains two components: (a) self-assessment and (b) self-recording. Determining whether a behavior has or has not occurred is self-assessment. Students may self-assess many aspects of a specific behavior (e.g., occurrence, duration, intensity, frequency). Although self-assessment can be done alone, it works best for most students in combination with self-recording (Harris \& Graham, in press a). Because of this synergy, we will discuss self-monitoring as involving both self-assessment and self-recording. In practice, once students become adept at self-monitoring, they may choose to use self-assessment alone; however, selfrecording necessarily involves appraisal and thus will always be used in combination with self-assessment.

\section{Self-Assessment}

Self-assessment requires students to be "observers" of their own behaviors or cognitions. What can be self-monitored is not limited just to overt behaviors. For example, students might ask themselves whether they were paying attention during seatwork activity or they might count how many times they mentally rehearsed specific facts and generalizations for an upcoming test.

Because self-assessment prompts students to compare their performance to a criterion for acceptable performance, it is often a good idea (at least initially) to help students spell out the standards that constitute acceptable performance ("I am on-task when I am — ; or "I have completed a spelling practice when I correctly write my word without looking at my list"). Even more important, the task or procedure chosen for self-assessment should be meaningful to the student and realistic in terms of his or her abilities.

Because the basic goal for any self-regulation procedure is independent performance, students need to learn how to direct and manage their own self-assessments. Therefore, all self-assessment procedures must be appropriate to the student's functional or developmental level, or the teacher should provide support and assistance until the student can conduct the self-assessments independently. When providing support, the teacher should remember not to co-opt the selfassessment process; the "self" is the central component in self-monitoring.

An example of teacher support gathered from our own field experience involves students who self-assessed the number of times they correctly practiced a spelling word during a study period. As students used this procedure, the number of times they correctly practiced spelling words increased. One student, however, started having some difficulty in applying the procedure, as she had trouble counting past 50 and was completing many more practices than this. Rather than counting for her, which would possibly subvert the process, the teacher gave her paper with consecutively numbered slots for each practice response. When using the paper, the student was directed to mark out any incorrect response as it occurred and not to proceed to the next slot until she had substituted a correct response. When the student was finished studying, she simply determined what number she had stopped at and recorded this number on her graph.

Finally, even though students can self-assess many facets of performance, it is usually best to begin with one aspect that is well within the student's capabilities. Additional elements can be addressed following improvement in the initial area. Goal setting can play a role in this process. If goals have been set previousy, either the goals themselves or the procedures used to attain the goals can be self-assessed, with the criteria for acceptable performance stated in the goal. For example, a student might set a goal of reading 20 pages of an assigned book each day until finishing the book. The student could then self-assess the number of pages read each day until the terminal goal was met.

\section{Self-Recording}

Self-recording involves writing down the results of the assessment. Individual tally sheets, charts, or graphs are frequently used for self-recording. Because these media present a visual record of students' performance over time and allow them to see their progress graphically, students often find them to be highly motivating (Reid \& Harris, 1989). Interest- 


\section{Describing Words}

\section{Name}

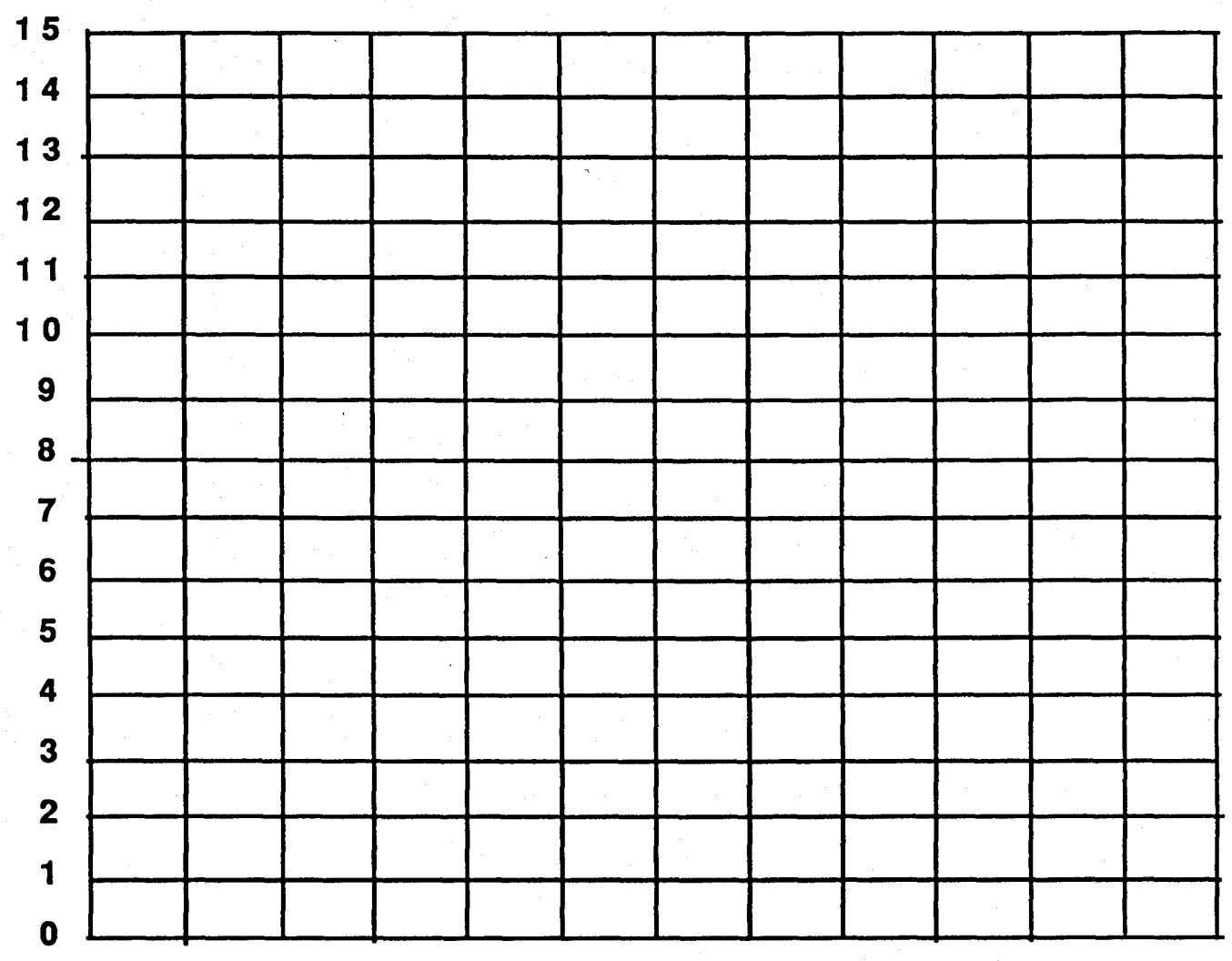

Date

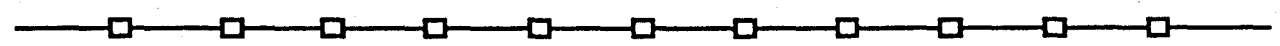

Fill in the number of describing words you used in your story.

FIGURE 1

Example of a simple recording graph.

Source: Adapted from Helping Young Writers Master the Craft: Strategy Instruction and Self-Regulation in the Writing Process by K. R. Harris and S. Graham, in press, Cambridge, MA: Brookline Books. Reprinted by permission. 


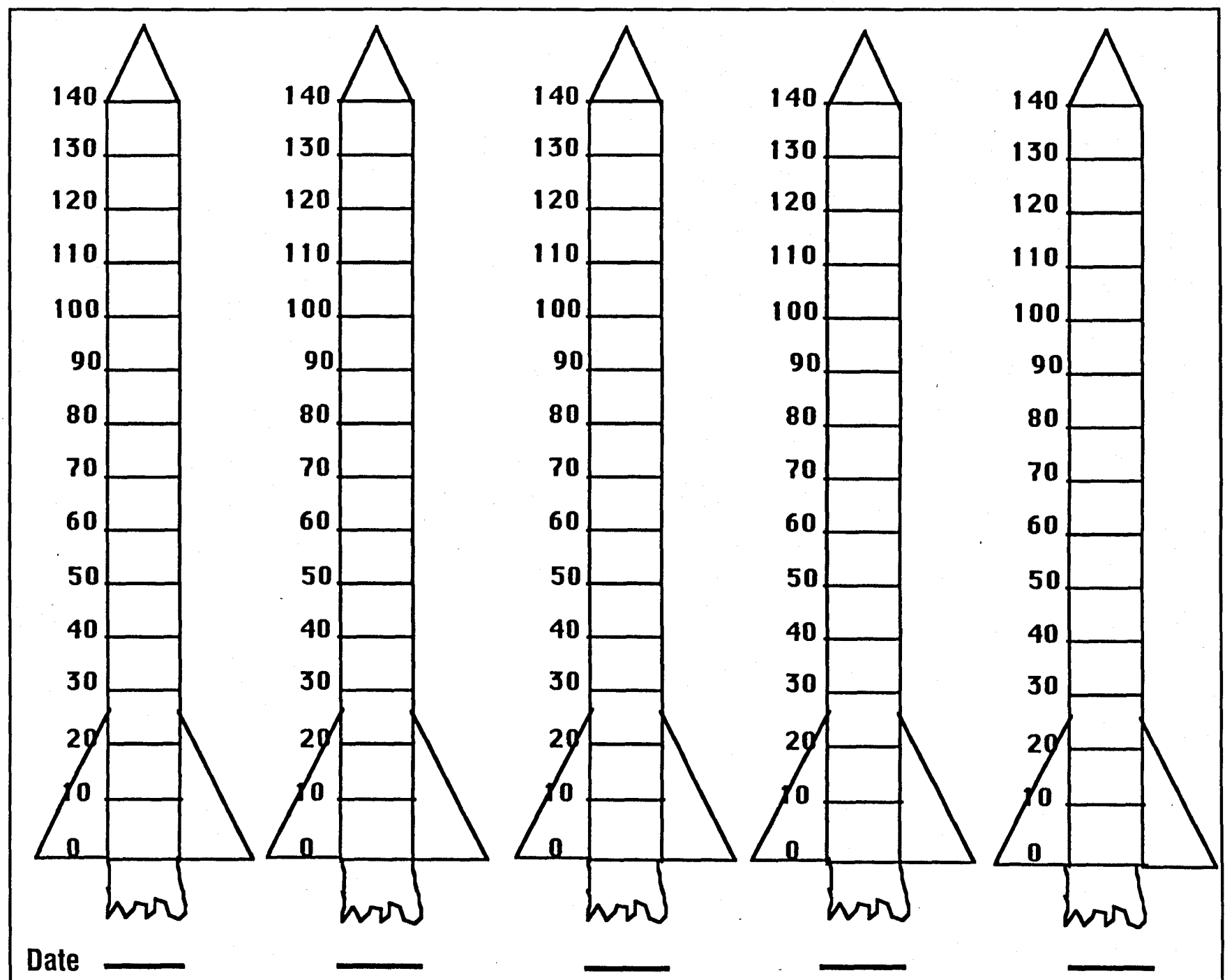

Fill in the number of problems you did correctly on the graph. FIGURE 2

Example of a recording system using rockets.

Source: Adapted from Helping Young Writers Master the Craft: Strategy Instruction and Self-Regulation in the Writing Process by K. R. Harris and S. Graham, in press, Cambridge, MA: Brookline Books. Reprinted by permission.

ingly, the use of graphs often results in spontaneous, unprompted goal setting. Self-recording graphs also may stimulate students to exceed previous performance levels. Sample self-recording graphs are shown in Figures 1 and 2.

\section{Teaching Self-Monitoring to Students}

Teaching students to self-monitor is straightforward. It often can be accomplished in only 15-30 minutes. After this initial instruction, students typically can use self-monitoring independently. The steps in teaching students to self-monitor are grounded empirically in research in both self-monitoring and cognition (e.g., Hallahan \& Sapona, 1983; Harris, 1986b; Mahoney \& Thoresen, 1974; Reid \& Harris, 1989). The steps presented should serve as a guide and are intended to be flexible. They should be modified as necessary to meet the needs of the teacher and the learner. 
Step 1. The first step involves determining and explicitly defining the target behavior the student will self-monitor. The target behavior ("behavior" is used broadly here; targets could be feelings, thoughts, academic products, processes for achieving a goal, etc.) or event should be defined clearly and precisely and must be easily understood by the student. For example, "doing good in math" might be a student's goal, but this would be nearly impossible for the student to self-monitor. More realistically, the student might monitor how many arithmetic problems were completed correctly during seatwork activities or on homework assignments and self-record the results using a graph such as the one shown in Figure 2. The student must be able to independently evaluate and selfrecord the behavior or event chosen for self-monitoring. The efficacy of self-monitoring may be reduced greatly if the student cannot independently self-assess the target behavior.

It is preferable for the teacher and the student to collaboratively determine target behaviors, define criteria, and establish monitoring and recording procedures. Although collaboration is generally preferable, in some instances the instructor may need to determine and define target behaviors and procedures prior to meeting with the student. The following steps should be followed and the general principles presented apply, however, regardless of whether behaviors are determined collaboratively or by the teacher.

Step 2. Before initiating any self-assessment or self-recording, the teacher should collect information on the student's current level of performance on the target behavior of interest. This need not be a laborious, time-consuming process. For the previous math problem example, information collection might simply involve obtaining past examples of work. In contrast, targets such as being on-task can be more difficult to assess. What is most important is to gain an accurate picture of the student's current performance, not to collect reams of data. One purpose of this information is to allow teachers to assess the effectiveness of the intervention. It also can support goal-setting and demonstrate progress after independent selfmonitoring has begun. One note of caution: If knowledge of present performance is going to be a negative experience for the student, it is preferable not to share this data.

Step 3. During this step the student learns about self-monitoring. The teacher or the student may put forward a target for self-monitoring (if the target for self-monitoring is not determined until this point, the operational defining of the target discussed in Step 1 should be done here as well). The teacher and the student would then briefly note why the target is important, and the teacher would introduce and discuss the rationale for self-monitoring, discuss the benefits the student will derive, and enlist the student's active cooperation and commitment. The need for the student's willing involvement is not a trivial issue; self-monitoring interventions are unlikely to succeed if students are merely told to self-monitor. With self-monitoring (and other self-regulation procedures), the student is the "active ingredient" and actually runs the intervention after the initial training. Consequently, the student must be an enthusiastic partner rather than a rote follower.

Although teachers should be enthusiastic about self-monitoring and present it in a favorable light, they should avoid sweeping promises or statements of unrealistic benefits. Selfmonitoring alone may not be sufficient for some students to improve their performance. For instance, weighing yourself each morning probably will not be enough to lose weight if you have no plans for cutting down what you eat or increasing exercise.

Step 4. After explaining the purpose of self-monitoring and gaining the student's cooperation, the teacher instructs the student in how to use the self-monitoring procedure (Steps 3 and 4 may occur together). In this step the teacher and student discuss (a) what will be self-assessed (e.g., the number of long-division problems correctly completed), (b) the criterion for success (e.g., follow all the division steps and get the correct answer), (c) how to self-record the target behavior (e.g., count up all the problems that met the criterion and graph the number), and (d) when self-monitoring will be done (e.g., during the practice session in the morning).

We use the following procedure with many students to help them learn to self-monitor: The teacher (or another student who has facility with self-monitoring) models the process, verbalizing what is being done at each step. Next the teacher asks the student to verbalize the steps and provides support when necessary. After the student can successfully verbalize the steps, he or she models and verbalizes them independently. Finally, the teacher and the student decide on a time to evaluate the effectiveness of self-monitoring and assess the student's reaction to the self-monitoring procedure. Some students are able to learn to self-monitor with a simple explanation and demonstration; adequate instruction, however, is a must, as the student must clearly understand the self-monitoring procedure to be able to carry it out independently.

When independent self-monitoring begins, the teacher should determine if the student is correctly performing the self-monitoring procedure. The self-monitoring procedure has to be carried out correctly and on a regular basis. If the procedure evokes confusion or problems, a short booster session to review or reteach the procedure should be conducted. Some students may benefit from (at least in the beginning stages) aids such as cards with the self-monitoring steps printed on 
them as a reminder. Teachers often need not be too concerned if self-recorded data are not extremely accurate; accuracy does not seem to be critical for self-monitoring interventions to be effective (Hallahan \& Sapona, 1983; O'Leary \& Dubey, 1979). If self-monitoring seems to be done correctly but does not result in improved performance, it may be necessary to teach the student to self-record more accurately, provide feedback or reinforcement (preferably social reinforcement) for accurate self-monitoring, or change the target behavior that is self-monitored.

If self-monitoring is agreeable to the student and is effective, self-monitoring should continue until the student and the teacher agree that it is no longer necessary. In practice, students enjoy using self-monitoring procedures, and self-monitoring can be used over long periods (Hallahan \& Sapona, 1983; Harris, 1986b; Reid \& Harris, 1989).

\section{Practical Considerations}

Self-monitoring is not a learning strategy. It should not be done exclusively to develop a skill or to teach new skills. Teaching students to self-monitor the number of division problems completed correctly, for instance, will have little effect if the student does not possess an effective long-division strategy (Reid \& Harris, 1989). For self-monitoring to have meaningful effects, students must have the ability or knowledge to perform the process or to create the product that will be self-monitored. Self-monitoring also can be combined effectively with other instructional techniques such as strategy instruction (see Harris \& Graham, 1985, for an example).

Teachers should not combine self-monitoring with rewards that are contingent on students' self-recorded data. Rewards based on students' self-records often lead to cheating or inaccurate self-recording. The student's focus then shifts from self-regulating to obtaining the reward. Students' self-recording is typically accurate, and self-monitoring is effective without extrinsic rewards or reinforcers (e.g., Hallahan \& Sapona, 1983; Reid \& Harris, 1989).

Although the student actually runs the intervention, the teacher has to show interest, to regularly evaluate the student's self-records, and to give positive social reinforcement for effort and achievement. With a supportive teacher, selfmonitoring is pleasant and students are willing to self-monitor over long periods. In our experience, students often choose to continue self-monitoring even when given the option to stop.

Finally, deciding when or if self-monitoring should be terminated or a new target should be set should be done collaboratively. If a decision is made to terminate self-monitoring, the teacher and the student may want to phase out self-monitoring gradually rather than abruptly. A "weaning process" is often desirable; it can lead to maintenance of performance gains. This could be done by gradually cutting back on the days when the student self-monitors or by eliminating a step or more in the self-monitoring process (e.g., eliminating the self-recording step and using only self-assessment).

\section{SELF-REINFORCEMENT}

Self-reinforcement occurs when a student chooses a reinforcer and self-administers it when a criterion for performance has been met or exceeded. Self-reinforcement can be used alone and may be as effective as teacher-administered reinforcement (cf. O'Leary \& Dubey, 1979; Rosenbaum \& Drabman, 1979). In principle, self-reinforcement requires students to have full control over available reinforcers and freely impose contingencies for the self-administration of these reinforcers in the relative absence of any external influences (i.e., without the teacher's supervision). In the classroom, this level of control may not be possible, at least initially. As with all self-regulation processes, the effective transition from collaborative evaluation and reinforcement from others to self-evaluation and reinforcement is often gradual.

This process is analogous to the natural development of other self-regulation processes (Zimmerman \& Schunk, 1989). At first, parents and other adults provide the child with standards for reinforcement. The child learns through interactions with adults that meeting or exceeding standards usually produces a positive response and that failing to meet standards may evoke little response or a negative response. Gradually children come to respond to their own behavior in selfrewarding (or self-punishing) ways. Whereas self-punishment is inadvisable, helping students to learn to self-reinforce, or to improve self-reinforcement procedures already in place, should play an integral role in helping them become self-regulated learners.

In practice, self-reinforcement usually is not done by itself. Rather, it is employed in conjunction with the other self-regulation procedures already discussed in this article. For example, we have found that many students respond nicely to simple, self-reinforcing statements (as discussed in the previous section on self-instruction) when they are used in combination with goal setting or self-monitoring. Using positive selfstatements as a form of self-reinforcement tends to be easy for students to do and follows naturally from both goal setting and self-monitoring. It is hard to imagine students reaching meaningful goals and not rewarding themselves with positive self-statements. 


\section{Teaching Self-Reinforcement to Students}

Self-reinforcement involves four basic components (Harris \& Graham, in press a):

1. Determining the standards for earning a reward.

2. Selecting the reinforcer to be earned.

3. Evaluating performance.

4. Self-administering the reinforcer.

Students can be taught to self-reinforce both as they work and once a task or product has been completed. For example, as they work, students can self-reinforce the completion of subgoals for accomplishing the task, the generation of a new idea for completing the task, and so forth.

In helping students learn to apply self-reinforcement principles, the teacher and the student both need to play an active role. To illustrate, in initiating the change from other-reinforcement to self-reinforcement, the teacher and the student can set performance levels that will earn an agreed-upon amount of reinforcement. For example, if increasing the rate of homework completion is a desirable goal, the teacher and the student can jointly set standards for reinforcement. If the student wants more time on the computer (student-determined reinforcer), the teacher and student could look at the student's rate of homework completion and decide that each homework assignment successfully completed will earn the student 3 minutes of computer time.

During the initial phase of implementation, the teacher might (depending upon the child's age and competence) be responsible for ascertaining that the homework has been completed successfully; however, the teacher and the student would gradually shift responsibility to the student. When this occurs, the teacher becomes an observer, offering suggestions and advice when the need arises.

\section{Practical Considerations}

With self-reinforcement, one of the first issues that must be addressed is to determine the level or standard of performance that must be obtained for reinforcement to be forthcoming. As noted in the section on goal setting, many students need guidance during this step to set reasonable and appropriate standards. Students may, for example, adopt a lenient standard of performance. In helping students learn to self-reinforce, stringent standards usually result in higher performance levels than do lenient standards. Nonetheless, the level at which standards are set should be tempered by knowledge of students' abilities and current functional levels. "Stringent" is a relative term. What is lenient for one student may be unrealistic for another.
Students who set overly lenient standards for themselves may need prompting on more appropriate standards or may need the teacher's assistance in setting realistic standards. One approach is to allow fairly lenient standards initially but to increase the standards progressively. This method is particularly helpful with students who lack confidence or who have a great deal of anxiety regarding the target task. Conversely, some students set unrealistically high standards. This is not good, because self-reinforcement is unlikely to occur. These students also need assistance in setting reasonable expectations for themselves.

Similar problems arise when students evaluate their progress toward the goals or standards they plan to self-reinforce. Some students judge their own performance more harshly than their teacher does; others are easier on themselves than the teacher is. To obtain accurate self-evaluations, some students need to work closely with the teacher at first. Accurate self-evaluations are particularly difficult for students when less objective processes and products are to be evaluated, such as how well they cleaned up after an art project or how well they understood a reading assignment. For this reason, self-reinforcement instruction should begin with more concrete aspects of performance such as: (a) Were all the parts of an essay present? or (b) How many comprehension questions did I answer correctly?

The actual procedure a student uses to self-reinforce should be clear and specific. In our experience, if these procedures are determined conjointly by the teacher and the student, they work best. Making a concrete record of the procedure to be employed is a good idea. This avoids misunderstandings and also gives the student a written set of steps to follow if he or she needs a reminder.

While self-reinforcement is occurring, the teacher should administer social reinforcement, especially social reinforcement for engaging in self-reinforcement. This need not be elaborate; praise, a hug, smile, or pat on the back will do the job nicely. Social reinforcement should continue throughout the intervention. Social reinforcement from peers, parents, and teachers continues to be important. Over time, students should be encouraged to shift from tangible reinforcers (if these are being used) to self-praise and positive self-statements. These forms of reinforcement may eventually replace tangible reinforcers to a great extent; even competent adult performers (such as the authors of this article) however, sometimes welcome tangible self-reinforcement.

Finally, students' motivational characteristics often play an important role in the success or failure of self-reinforcement. Students who are motivated by feelings of self-satisfaction and who view success or failure as a function of their effort 
(or lack of effort) may respond positively to self-reinforcement and find that it results in better performance. In contrast, students who see success or failure as the result of external agencies and as being fundamentally beyond their control may have more difficulty with self-reinforcement. This does not contraindicate the use of self-reinforcement with these students. On the contrary, it may help instill motivation based on self-satisfaction and help them recognize the importance of their own efforts. These students, however, may require a more gradual transition from teacher reinforcement to self-reinforcement, more time and assistance to attain competence in using self-reinforcement, and help in developing effort attributions (cf. Licht, 1983).

\section{CONCLUSIONS}

Even though the development of self-regulation processes is an important part of learning and maturing, we would not advocate self-regulation instruction with every student in every setting. Some children already possess effective self-regulation strategies. In fact, some children are so good at regulating their behavior that they regulate not only their own behavior but that of their peers and sometimes their teachers as well (Meichenbaum \& Beimiller, in press). We would like to encourage the reader, however, to apply the types of procedures and strategies discussed here as a complement or possible alternative to more traditional procedures. Exclusive reliance on methods that are solely directed and administered by others with students who have difficulty regulating their own behavior may well be teaching a hidden curriculumnamely, that only others can control the student's behavior. One of the primary values of teaching students procedures for regulating their own behavior is that is provides them with basic and powerful tools for self-empowerment.

\section{REFERENCES}

Bandura, A., \& Schunk, D. (1981). Cultivating competence, self-efficacy, and intrinsic interest through proximal self-motivation. Journal of Personality and Social Psychology, 41, 586-598.

Bandura, A., \& Simon, K. (1977). The role of proximinal intentions in selfregulation of refractory behavior. Cognitive Therapy \& Research, 1 , 177-193.

Brown, A., \& Campione, J. (1981). Inducing flexible thinking: A problem of access. In M. Freidman, J. Das, N. O'Connor (Eds.), Intelligence and learning (pp. 515-529). New York: Plenum.

Fuson, K. (1979). The development of self-regulating aspects of speech: A review. In G. Zivin (Ed.), The development of self-regulation through private speech (pp. 135-218). New York: Wiley.

Graham, S. (1983). The effects of self-instructional procedures on LD students' handwriting performance. Learning Disability Quarterly, 6, 231-234.
Graham, S., \& Harris, K. R. (1987). Improving composition skills of inefficient learners with self-instructional strategy training. Topics in Language Disorders, 7, 66-77.

Graham, S., \& Harris, K. R. (1989). Cognitive training: Implications for written language. In J. Hughes \& R. Hall (Eds.), Cognitive behavioral psychology in the schools: A comprehensive handbook (pp. 247-279). New York: Guilford.

Graham, S., \& Harris, K. R. (in press). Self-instructional strategy development: Programmatic research in writing. In B. Wong (Ed.), Intervention research with students with learning disabilities: An international perspective. New York: Springer Verlag.

Graham, S., Harris, K. R., MacArthur, C., \& Schwartz, S. (1991). Writing and writing instruction with students with learning disabilities: A review of a program of research. Learning Disability Quarterly, 14, 89-114.

Graham, S., Harris, K. R., \& Sawyer, R. (1987). Composition instruction with learning disabled students: Self-instructional strategy training. $F o$ cus on Exceptional Children, 20, 1-11.

Graham, S., MacArthur, C., Schwartz, S., \& Voth, T. (in press). Improving LD students' compositions using a strategy involving product and process goal-setting. Exceptional Children.

Gresham, F. (1985). Utility of cognitive-behavioral procedures for social skills training with children: A critical review. Journal of Abnormal Child Psychology, 13, 411-424.

Hallahan, D. P., \& Sapona, R. (1983). Self-monitoring of attention with learning disabled children: Past research and current issues. Journal of Learning Disabilities, 16, 616-620.

Harris, K. R. (1982). Cognitive-behavior modification: Application with exceptional students. Focus on Exceptional Children, 15, 1-16.

Harris, K. R. (1986a). The effects of cognitive-behavior modification on private speech and task performance during problem solving among learning disabled and normally achieving children. Journal of Abnormal Child Psychology, 14, 63-76.

Harris, K. R. (1986b). Self-monitoring of attentional behavior vs. self-monitoring of productivity: Effects on on-task behavior and academic response rate among learning disabled children. Journal of Applied Behavior Analysis, 19, 417-423.

Harris, K. R. (1990). Developing self-regulated learners: The role of private speech and self-instructions. Educational Psychologist, 25, 35-50.

Harris, K. R., \& Graham, S. (1985). Improving learning disabled students' composition skills: Self-control strategy training. Learning Disability Quarterly, 8, 27-36.

Harris, K. R., \& Graham, S. (in press a). Helping young writers master the craft: Strategy instruction and self-regulation in the writing process. Boston: Brookline Books.

Harris, K. R. \& Graham, S. (in press b). Self-regulated strategy development: A part of the writing process. In M. Pressley, K. R. Harris, \& J. Guthrie (Eds.), Promoting academic competence and literacy: Cognitive research and instructional innovation. New York: Academic Press.

Johnson, L., \& Graham, S. (1990). Goal setting and its application with exceptional learners. Preventing School Failure, 34, 4-8.

Latham, G., \& Yukl, G. (1975). A review of research on the application of goal setting in organizations. Academy of Management Journal, 18, 824-845.

Licht, B. (1983). Cognitive-motivational factors that contribute to the achievement of learning-disabled children. Journal of Learning Disabilities, 16, 483-490.

Locke, E., Shaw, K., Saari, L., \& Latham, G. (1981). Goal setting and task performance: 1969-1980. Psychological Bulletin, 90, 125-152. 
Mahoney, M., \& Thoresen, C. (Eds.) (1974). Self-control: Power to the person. Belmont, CA: Wadsworth.

Masters, J., Furman, W., \& Barden, R. (1977). Effects of achievement standards, tangible rewards, and self-dispensed achievement evaluations on children's task mastery. Child Development, 48, 217-224.

Meichenbaum, D. (1977). Cognitive behavior modification: An integrative approach. New York: Plenum Press.

Meichenbaum, D., \& Biemiller, A. (in press). In search of student expertise in the classroom: A metacognitive analysis. In M. Pressley, K. R. Harris, \& J. Guthrie (Eds.), Promoting academic competence and literacy: Cognitive research and instructional innovation. New York: Academic Press.

Meichenbaum, D., \& Goodman, S. (1979). Clinical use of private speech and critical questions about its study in natural settings. In G. Zivin (Ed.), The development of self-regulation through private speech (pp. 325-360). New York: Wiley.

Nelson, R. O. (1977). Methodological issues in assessment via self-monitoring. In J. D. Cone \& R. P. Hawkins (Eds.), Behavioral Assessment: New directions in clinical psychology. New York: Brunner/Mazel.

O'Leary, S., \& Dubey, D. (1979). Applications of self-control procedures by children: A review. Journal of Applied Behavior Analysis, 12, 449-465.

Reid, R., \& Harris, K. R. (1989). Self-monitoring of performance. $L D F O$ rum, $15,39-42$.

Rosenbaum, M., \& Drabman, R. (1979). Self-control training in the classroom: A review and critique. Journal of Applied Behavior Analysis, 18, $467-485$.
Sawyer, R., Graham, S., \& Harris, K. R. (1991). Theoretically based effects of strategy instruction on learning disabled students' acquisition, maintenance, and generalization of composition skills and self-efficacy. Manuscript submitted for publications.

Scardamalia, M., \& Bereiter, C. (1985). Fostering the development of selfregulation in children's knowledge processing. In S. Chipman, J. Segal, \& R. Glaser (Eds.), Thinking and learning skills: Current research and open questions (Vol. 2, pp. 563-577). Hillsdale, NJ: Lawrence Erlbaum.

Schunk, D. (1985). Participation in goal setting: Effects on self-efficacy and skills of learning-disabled children. Journal of Special Education, 19, 307-317.

Schunk, D. (1989). Self-efficacy and cognitive achievement: Implications for students with learning disabilities. Journal of Learning Disabilities, 22, $14-22$.

Vygotsky, L. (1962). Thought and language. Cambridge, MA: MIT Press (Original work published 1934).

Wong, B. Y. L., \& Jones, W. (1982). Increasing metacomprehension in learning-disabled and normally-achieving students through self-questioning training. Learning Disability Quarterly, 5, 228-240.

Zimmerman, B., \& Schunk, D. (1989). Self-regulated learning and academic achievement: Theory, research, and practice. New York: Springer Verlag.

Zivin, G. (Ed.). (1979). The development of self-regulation through private speech. New York: Wiley.

\section{PERMISSIONS AND COPYRIGHT}

All rights are reserved. No part of this publication may be reproduced, photocopied, faxed, stored in a retrieval system, or transmitted, in any form or by any means, electronic, mechanical, recording or otherwise, without the prior written permission of the publisher.
Back issues are available for sale. Reproduction requires permission and payment of fees. It is illegal and a violation of Federal copyright law to reproduce this publication without permission. Direct all inquiries to the permissions editor. 